\title{
Millisecond timing on the IBM PC/XT/AT and PS/2: A review of the options and corrections for the Graves and Bradley algorithm
}

\author{
ROGER E. GRAVES and RON BRADLEY \\ University of Victoria, Victoria, British Columbia, Canada
}

\begin{abstract}
Eleven methods of obtaining millisecond timing on the IBM microcomputer family are briefly reviewed. In our view, the approach recommended by Smith and Puckett (1984) has the fewest limitations, but it must be modified to prevent rare, yet unacceptable, errors. The modified algorithm has been presented for Turbo Pascal, C, and in the present paper, for BASIC and QuickBASIC.
\end{abstract}

Controlling behavioral applications with the IBM PC family of computers frequently requires accurate timing capability. The hardware timer in these computers counts in submicrosecond units for about $55 \mathrm{msec}$ and then generates an interrupt that increments a BIOS time counter. Since most programming languages provide a time function that only accesses the BIOS counter, timing resolution is limited to $55 \mathrm{msec}$. Languages with higher resolution timing functions have not provided sufficient documentation of the actual accuracy and reliability of the timing on various machines. Consequently, specialized and well-documented timing algorithms have had to be developed.

Smith and Puckett (1984) discussed two basic approaches to this problem. The first involves reprogramming the hardware timer to generate an interrupt every $1 \mathrm{msec}$ and modifying the timer interrupt to maintain a separate count in units of $1 \mathrm{msec}$ rather than units of $55 \mathrm{msec}$. Smith and Puckett concluded that this approach was unsatisfactory, because: (1) The overhead of servicing an interrupt 1,000 times per second meant that an IBM PC would spend $16 \%$ of the time doing only this function (faster machines would require less time), and (2) the choice of BIOS memory locations and DOS interrupt handling may not be compatible with other applications or not be supported by later DOS and BIOS versions. It would also appear that the frequency of interrupts could in itself lead to conflicts with other functions using or disabling interrupts. Furthermore, interval timing accuracy is inherently subject to errors of up to $2 \mathrm{msec}$ if the basic

Preparation of this article was supported by Grant OGP0001021 from the Natural Sciences and Engineering Research Council of Canada. Requests for reprints should be sent to Roger Graves, Department of Psychology, University of Victoria, P.O. Box 3050, Victoria, BC V8W 3P5, Canada, or to E-mail address RG @ UVVM.UVIC.CA. resolution is only $1 \mathrm{msec}$. Bührer, Sparrer, and Weitkunat (1987) provided an implementation of this approach with an assembly language subroutine that could be called from BASIC. Their specific method had the further limitation of timing intervals no longer than $65 \mathrm{sec}$ and of causing the loss of normal BIOS time-of-day information. This approach has also been implemented in $\mathrm{C}$ (Dlhopolsky, 1988) and Turbo Pascal (Brysbaert, Bovens, d'Ydewalle, \& Van Calster, 1989; Heathcote, 1988). Of these versions, Dlhopolsky's (1988) is unique in not requiring modification of the timer interrupt and for restoring the BIOS time of day after timing has concluded. Thus, this last version avoids most of the disadvantages of this approach.

Smith and Puckett (1984) actually outlined an implementation of the first approach that avoids loss of the BIOS time-of-day function by saving the millisecond counts separately and by updating the BIOS fields at the correct intervals. Creeger, Miller, and Paredes (1990) have provided a sophisticated implementation of what Smith and Puckett (1984) outlined, together with interfaces for all the popular programming languages. Their method appears to be quite useful, but it remains subject to the limitations described above. We found that, as Smith and Puckett foresaw, the Creeger et al. (1990) TSR interrupt handler failed to install on one system because another TSR had already defined a DOS timer interrupt function. Other routines that might slow or degrade the normal timer service should ideally not be used with any of the timing schemes discussed herein.

Smith and Puckett (1984) recommended a second approach that involved obtaining the submicrosecond units timing information from the IBM PC/XT hardware timer for adding to the low-resolution BIOS time counts. This approach does not interfere with normal BIOS or DOS function, does not increase the interrupt overhead, and 
can provide interval timing accuracy to less than $1 \mathrm{msec}$. This method has continued to be applicable for the IBM AT and PS/2 successors to the PC and for most of the clone versions. We provided an assembly language implementation of this Smith and Puckett method, together with instructions for calling the subroutine from IBM BASICA (or Microsoft GW-BASIC; Graves \& Bradley, 1987) and from Microsoft QuickBASIC (Graves \& Bradley, 1988). This implementation was included in a QuickBASIC tachistoscope application library devised by Segalowitz (1988). Emerson (1988) took another approach to reading the hardware timer information, which had the disadvantage of working only with AT-class machines and only with a specific version of the $C$ language. Granaas's (1989) modification of Emerson's (1988) approach allows the use of other $C$ languages, but still excludes PC/XT machines. Because Emerson's and Granaas's methods do not reprogram the timer to mode 2 , they can only work on machines with a newer type timer chip that provides an additional status bit. We see no advantage to this, and the loss of applicability to the older PC/XT machines is a clear disadvantage.

Crosbie (1989) described yet another implementation, a combination of Smith and Puckett's (1984) two approaches, which reads the high-resolution hardware timer information from Turbo Pascal but which also modifies the timer interrupt to maintain a separate count of the number of elapsed 55-msec intervals. It would appear that Crosbie's (1989) method is subject to the type of timing error discovered by Bovens and Brysbaert (1990), and that it has the potential of conflicting with other routines attempting timer intercepts.

According to our review, the approach that Smith and Puckett (1984) recommended still appears to be preferable. Bovens and Brysbaert (1990), however, discovered that the original algorithm occasionally yields times that are in error by $55 \mathrm{msec}$. Beringer (in press) has further discussed the source of the problem and reported that the Smith and Puckett (1984) algorithm, as implemented by Graves and Bradley (1987), yields a 55-msec error on $2 / 65535$ calls. We have confirmed this error rate, using a 25-MHz 80386 AT-type clone, and found errors to be about twice as frequent on the slower IBM XT. Bovens and Brysbaert (1990) have devised a straightforward modification of the original algorithm that prevents the errors, and they have presented an implementation of it for the Turbo Pascal language. Beringer (in press) has implemented a version of the Bovens and Brysbaert (1990) modification for the $C$ language. The listing in the Appendix shows how Beringer's (in press) version of the Bovens and Brysbaert (1990) modification can be added to the Graves and Bradley (1987) TMRREAD assembly language subroutine. This subroutine is designed to return timing information in the proper format for BASICA, GW-BASIC, and QuickBASIC. Our testing yielded no errors in several million QuickBASIC 4.50 calls on an IBM XT and several 80286 and 80386 clones. The approach recommended by Smith and Puckett (1984), with the needed modification, is thus now available to users of QuickBASIC, C, and Turbo Pascal.

Availability. A diskette containing ASCII and .OBJ versions of TMRREAD2, QuickBASIC 4.50 libraries containing the modified timing subroutine plus the other routines described by Graves and Bradley (1988), and sample programs illustrating how the subroutines can be called from BASICA (or GWBASIC) and from QuickBASIC is available from Roger Graves for $\$ 10$ (Canadian) to cover materials, postage and handling.

\section{REFERENCES}

BERINGer, J. (in press). Notes on Graves and Bradley's timer algorithm. Behavior Research Methods, Instruments, \& Computers.

Bovens, N., \& BrysbaerT, M. (1990). IBM PC/XT/AT and PS/2 Turbo Pascal timing with extended resolution. Behavior Research Methods, Instruments, \& Computers, 22, 332-334.

Brysbaert, M., Bovens, N., D'Ydewalle, G., \& Van Calster, J. (1989). Turbo Pascal timing routines for the IBM microcomputer family. Behavior Research Methods, Instruments, \& Computers, 21, 73-83.

Bührer, M., SPARRER, B., \& WeitKunat, R. (1987). Interval timing routines for the IBM PC/XT/AT microcomputer family. Behavior Research Methods, Instruments, \& Computers, 19, 327-334.

Creeger, C. P., Miller, K. F., \& Paredes, D. R. (1990). Micromanaging time: Measuring and controlling timing errors in computer-controlled experiments. Behavior Research Methods, Instruments, \& Computers, 22, 34-79.

Crosbie, J. (1989). A simple Turbo Pascal 4.0 program for millisecond timing on the IBM PC/XT/AT. Behavior Research Methods, Instruments, \& Computers, 21, 408-413.

DLhopolsky, J. G. (1988). C language functions for millisecond timing on the IBM PC. Behavior Research Methods, Instruments, \& Computers, 20, 560-565.

Emerson, P. L. (1988). TIMEX: A simple IBM AT C language timer with extended resolution. Behavior Research Methods, Instruments, \& Computers, 20, 566-572.

GranaAs, M. M. (1989). TIMEX2: A modified C-language timer for PC AT class machines. Behavior Research Methods, Instruments, \& Computers, 21, 619-622.

Graves, R., B Bradley, R. (1987). Millisecond interval timer and auditory reaction time programs for the IBM PC. Behavior Research Methods, Instruments, \& Computers, 19, 30-35.

Graves, R., Bradley, R. (1988). More on millisecond timing and tachistoscope applications for the IBM PC. Behavior Research Methods, Instruments, \& Computers, 20, 408-412.

HeAthCOTE, A. (1988). Screen control and timing routines for the IBM microcomputer family using a high-level language. Behavior Research Methods, Instruments, \& Computers, 20, 289-297.

SEgalowitz, S. J. (1988). IBM PC tachistoscope: II. Assembly language subroutines. Behavior Research Methods, Instruments, \& Computers, 20, 432.

SMTth, B., \& PucxetT, T. (1984, April). Life in the fast lane. PC Technical Journal, pp. 63-74. 
APPENDIX

Listing of Modifications to TMRREAD.ASM

(Retain original code through and including the following XCHG AH,AL.)<smiles>[AlH2]</smiles>

IN

AL,TIMER $\_0$

;get 8253 count

MOV

$\mathrm{AH}, \mathrm{AL}$

NOP

AL, TIMER_0

STI

XCHG

AH,AL ;put timer count in correct order

(Insert the following code.)

;Test to determine if timer count near BIOS update point

TEST

$\mathrm{JZ}$

CLI

MOV

MOV

STI

;End test

$\begin{array}{lll}\text { OK : NOT } & \text { AX }\end{array}$

$\mathrm{AH}, 80 \mathrm{H}$

OK

BX,TIMER_LOW

CX,TIMER_HIGH ;if timer count $<10000000 \mathrm{~b}$

;no overflow problem exists

; disable interrupts

;get BIOS timer values again

;enable interrupts

(Retain original code from and including the following $X C H G A X, C X$.)

XCHG

$\mathrm{AX}, \mathrm{CX}$

SUB $\quad A X, 32768$

SUB $\quad B X, 32768$

; set up data for BASIC

;integers

(Manuscript received April 23, 1991;

accepted for publication May 8, 1991.) 